\title{
Early Outcome of Surgical Repair of Complete Atrioventricular Canal Defects (Comparative Study Between Children before and after 6 Months of Age)
}

\author{
Ayman Mohamed Khalifa ${ }^{1, *}$ MSc., Elhusseiny Elhuseiny Gamil ${ }^{2}$ MD., Mohamed Eldesoky \\ Sharaa $^{2}$ MD. and Bahaa Abd El Gawad El Khonezy ${ }^{2}$ MD.
}

\author{
* Corresponding Author: \\ Ayman Mohamed Khalifa \\ aymankhalifa87@gmail.com
}

Received for publication March 14, 2021; Accepted July 30, 2021; Published online July 30, 2021.

Copyright The Authors published by Al-Azhar University, Faculty of Medicine, Cairo, Egypt. Users have the right to read, download, copy, distribute, print, search, or link to the full texts of articles under the following conditions: Creative Commons Attribution-Share Alike 4.0 International Public License (CC BY-SA 4.0)

doi: 10.21608/aimj.2021.57675.1400

${ }^{I}$ Department of Cardiothoracic Surgery, Atfal Misr Hospital, Cairo, Egypt.

${ }^{2}$ Department of Cardiothoracic Surgery, Faculty of Medicine, AlAzhar University, Cairo, Egypt.

\begin{abstract}
Background: Complete atrioventricular septal defect (CAVSD) is composed of a primum atrial septal defect, nonrestrictive inlet ventricular septal defect and common atrioventricular (AV) valve.

The aim of the work: to compare the result of surgical repair of complete atrioventricular (CAVC) before and after six months of age.

Patients and Methods: Between January 2018 and December 2019 at Al-Azhar University and Atfal Misr hospital, 80 patients underwent CAVC repair. These patients were divided into 2 groups according to the age and each group is of 40 patients. These patients were managed by modified patch and double patch techniques.

Results: In-group A, the mortality was four operative deaths, four patients with severs mitral reguigitation and mean pulmonary artery pressure $30-55 \mathrm{mmHg}$. While in the group $\mathrm{B}$, there were seven operative deaths, two patients with severs mitral reguigitation and mean pulmonary artery pressure $50-65 \mathrm{mmHg}$.

Conclusion: Early repair improve the pulmonary artery pressure with high incidence of surgical reintervention for $\mathrm{Lt} \mathrm{AV}$ valve, while late repair improve the results for Lt AV valve but has a lower effect on the pulmonary artery pressure.
\end{abstract}

Keywords: Repair; CAVC; Pediatric; Six; Months.

Disclosure: The authors have no financial interest to declare in relation to the content of this article. The Article Processing Charge was paid for by the authors.

Authorship: All authors have a substantial contribution to the article.

\section{INTRODUCTION}

Complete atrioventricular septal defect (CAVSD) is composed of a primum atrial septal defect, nonrestrictive inlet ventricular septal defect and common atrioventricular (AV) valve. ${ }^{1}$

Down syndrome patients have high incidence of pulmonary vascular obstructive disease (PVOD) ${ }^{2}$ that increase the morbidity and mortality rate. This syndrome is a predisposing factor to increase the intraoperative complications, the need for mechanical ventilation and long ICU and hospital stay. ${ }^{3}$

Early in life, these patients are complaining of failure to thrive and recurrent chest infection which is life threating, not responding to medical treatment and may contraindicate the primary repair. ${ }^{4}$

Echocardiography allows direct visualization of the defect spectrum and often a large defect of the midline heart structures are seen. Color Doppler often aids in further visualization of the central opening. An AVSD can give a classical "Gooseneck" sign on a lateral left ventricular angiogram. ${ }^{5}$

Over the last years, there is an advancement of repair of CAVSD starting from two staged technique by pulmonary artery banding then total repair to primary total repair in early life. Accurate diagnosis of the pathology with perfect orientation of the surgical anatomy played an important role in the development the surgical result. Also, how to manage the pulmonary hypertensive crisis, myocardial protection during surgery and the postoperative care are important factors in reducing the mortality and reoperation rate. ${ }^{6}$

The ideal timing and the operative technique for the management of CAVSD is still debate. Many authors preferred early intervention as it avoids the pulmonary hypertension development. ${ }^{7}$

\section{PATIENTS AND METHODS}

This study is prospective, comparative, non-blinded and multicenter. In the department of cardiothoracic surgery at AL - Azhar university and Atfal Misr hospital, the study was done on 80 patients divided into 2 groups; group A included 40 patients below six months of age and group B included 40 patients after six months of age.

This study included all patients presented with isolated complete atrio-ventricular canal and excluded 
cases of complete atrio-ventricular canal associated with repairable congenital cardiac anomalies, unbalanced complete atrio-ventricular canal and redo cases.

In the preoperative period, we followed gender, age, body weight, laboratory tests, chest x-ray, echocardiography (size of VSD, degree of left AV valve regurgitation \& degree of pulmonary hypertension) and any medication used for heart failure and pulmonary hypertension.

Intraoperative, under general anesthesia, median sternotomy incision was the standard incision, The pericardium is opened, full dose of Heparin (300 unit/Kg) was administrated, cardiopulmonary bypass was instituted through aortic and bi-caval cannulation, PDA is looked for routinely and ligated if present prior to bypass and CPB was commenced with systemic cooling to moderate levels of hypothermia (28C). The aorta was cross-clamped and cold blood cardioplegia was administered into the aortic root. An oblique incision was made in the right atrium; cold saline is injected into the ventricles to approximate the $\mathrm{A}-\mathrm{V}$ valve in its closed position. The most anterior point of the left superior leaflet and left inferior leaflet opposing edges was found and a double-armed 6-0 polypropylene suture is placed through it and the cleft was repaired with interrupted sutures. In patients repaired with modified single patch technique, direct suture of the ventricular component, with placement of U sutures, with 5-0 or 6-0 polyester tied on a Dacron fabric to the right side of the ventricular septum. Then the sutures are passed through the antero-superior and postero-inferior valvular leaflets at appropriate sites, demarcating the limits of the right and left atrial outflow tracts, thus determining the size of the right and left AV valve orifices. After tying the ventricular stitches that close the ventricular component and fix the AV valves, the suture of the patch was completed continuously at the atrial level, with 5-0 or 6-0 polypropylene. In patients repaired with double patch technique, the interventricular patch (pericardial or synthetic) was sutured to the right side of the crest of the ventricular septum with continuous 5-0 or 6-0 polypropylene suture. The interatrial patch was then trimmed to appropriate shape and size, and the first part of its insertion is accomplished, then sutured along the edge of the defect. The heart is then re-warmed and deaired, the Aorta is de-clamped, de-airing of the heart is continued through an aortic root vent. The RA is closed with 5/0 poly-propylene, both caval snares are taken off, and rewarming completed. After stabilization of haemodynamics, patients were weaned from $\mathrm{CPB}$, the venous cannulae are removed, Heparin was neutralized with protamine, and then the arterial cannula was removed. Two retrosternal drainage tubes were inserted, as well as two temporary pace-maker wires which are attached to the $\mathrm{RV}$ wall and further two wires to the RA wall if dual chamber pacing was required. We recorded invasive measurement of pulmonary pressure, time of aortic cross clamp, time of total cardiopulmonary bypass, type of surgical technique and any complication occurring during the operation.
In the postoperative period, we followed dose and type of inotropes, period of ventilation, time of ICU and hospital stay, clinical examination, chest $\mathrm{x}$-ray, echocardiography and any postoperative complications before discharge as surgical bleeding, heart block and residual mitral regurgitation.

Follow up of the patients during the first 6 months after discharge by clinical examination, CXR and echocardiography with median follow up duration of 17 months.

Death during hospital stay or within 30 days after the operation was defined as (Early mortality).

\section{Statistical analysis:}

Statistical studies of preoperative, operative and postoperative data would include three main items, (1) Descriptive statistics: The main characteristics and parameters of the 80 patients in the 2 groups are summarized with the maximum, minimum, mean value and standard deviation for each variable is presented. (2) Analysis of variance: Most of the preoperative, operative and postoperative data are analyzed, the mean value of each variable of the two groups of patients is presented, the F-ratio (ANOVA test) and the probability ( $\mathrm{p}$ value) are shown to compare between different means. In most of the variables tested, there is significant difference between the two groups of patients. (3) Correlation of data: Most of the preoperative, operative and postoperative data are correlated with each other. The data of all patients (80) will be correlated with each other. Correlation matrix was done for the whole group of patients. The coefficient of correlation (r) was calculated for each correlation in all variables. The critical value for correlation was calculated in each correlation matrix. If the $(r)$ for a certain variable is above the critical value, the correlation is statistically significant, and if the (r) below the critical value, the correlation is statistically insignificant. A positive correlation means that when one variable increases, the other variable also increases and vice versa. A negative correlation means that when one variable increases the other decreases and vice versa.

\section{RESULTS}

In group A, the age of cases was ranging between 3 6 months with mean age $4.85 \pm 1.02$ month; the weight was ranging between $4-7.5 \mathrm{~kg}$ with mean weight $4.93 \pm 1.03 \mathrm{~kg}$. While in group $\mathrm{B}$, the age of cases was ranging between $6.5-11$ months with mean age $7.47 \pm 1.68$ month, the weight was ranging between $6-8.5 \mathrm{~kg}$ with mean weight $6.87 \pm 1.54 \mathrm{~kg}$. Table (1)

The $p$ value between the two groups was significant $(\mathrm{p}$ value $<0.05)$

\begin{tabular}{|c|c|c|c|}
\hline \multicolumn{2}{|c|}{} & Age (m) & Weight (kg) \\
\hline \multirow{2}{*}{ A } & Range & $3-6$ & $4-7.5$ \\
\cline { 2 - 4 } & Mean & $4.85 \pm 1.02$ & $4.93 \pm 1.03$ \\
\hline \multirow{2}{*}{ B } & Range & $6.5-11$ & $6-8.5$ \\
\cline { 2 - 4 } & Mean & $7.47 \pm 1.68$ & $6.87 \pm 1.54$ \\
\hline
\end{tabular}

Table 1: Age and weight of patients. 
31 patients $(77.5 \%)$ were with the features of Down syndrome in the group $\mathrm{A}$, while they were 27 patients $(67.5 \%)$ in group B.

According to Rastelli classification, in group A there were 31 patients $(77.5 \%)$ with type A, $9(22.5 \%)$ type $\mathrm{B}$ and no patient with type $\mathrm{C}$. While in group $\mathrm{B}$, they were $34(85 \%)$ with type A, 6 patients $(15 \%)$ with type $\mathrm{B}$ and no cases with type $\mathrm{C}$.

Symptoms of patients in group A were dyspnea on effort (during feeding) which was 33 patients $(82.5 \%)$, while dyspnea at rest was present in 2 patients $(5 \%)$. Recurrent chest infection occurred in 33 patients $(82.5 \%)$ and asymptomatic patients were 5 patients $(12.5 \%)$. While in group B there was dyspnea on effort (during feeding) in 38 patients $(95 \%)$, while dyspnea at rest was present in 2 patients $(5 \%)$ Recurrent chest infection occurred in 37 patients $(92.5 \%)$ and asymptomatic patients were 1 patient (2.5\%). Table (2)

\begin{tabular}{|l|c|c|c|c|}
\hline \multirow{2}{*}{\multicolumn{1}{|c|}{ Symptoms }} & \multicolumn{2}{|c|}{ A } & \multicolumn{2}{c|}{ B } \\
\cline { 2 - 5 } & No. & $\%$ & No. & $\%$ \\
\hline Dyspnea on effort (feeding) & 33 & 82.5 & 38 & 95 \\
\hline Dyspnea on rest & 2 & 5 & 2 & 5 \\
\hline Recurrent chest infection & 33 & 82.5 & 37 & 92.5 \\
\hline Asymptomatic & 5 & 12.5 & 1 & 2.5 \\
\hline
\end{tabular}

Table 2: Symptoms of patients.

All patients were investigated with plain chest $\mathrm{x}$-ray that showed increased cardiothoracic ratio in $100 \%$ of patients.

We diagnosed all patients with preoperative echocardiography that revealed:

In group A:

The range of ASD diameter was $12-18 \mathrm{~mm}$ with mean $13.24 \pm 1.74 \mathrm{~mm}$. The range of VSD diameter was $6-11 \mathrm{~mm}$ with mean $8.25 \pm 1.53 \mathrm{~mm}$. Systolic PAP ranges $45-80 \mathrm{mmHg}$ with mean $61.00 \pm 10.07$ $\mathrm{mmHg}$. The degree of right $\mathrm{AV}$ regurgitation was mild in 22 patients $(55 \%)$, moderate in 13 patients $(32.5 \%)$ \& severe in 5 patients $(12.5 \%)$. The degree of left AV regurgitation was mild in 15 patients $(37.5 \%)$, moderate in 18 patients $(45.0 \%) \&$ severe in 7 patients $(17.5 \%)$. Table (3)

In group B:

The range of ASD diameter was $11-19 \mathrm{~mm}$ with mean $12.02 \pm 1.32 \mathrm{~mm}$. The range of VSD diameter was $7-13 \mathrm{~mm}$ with mean $9.34 \pm 1.89 \mathrm{~mm}$. Systolic PAP ranges $60-90 \mathrm{mmHg}$ with mean $74.21 \pm 15.01$ mmHg. The degree of right AV regurgitation was mild in 14 patients $(35 \%)$, moderate in 18 patients $(45 \%) \&$ severe in 8 patients $(20 \%)$. The degree of left AV regurgitation was mild in 8 patients $(20 \%)$, moderate in 18 patients $(45.0 \%)$ \& severe in 15 patients $(37.5 \%)$.

The $\mathrm{p}$ value between the two groups according to pulmonary artery pressure and AVV valve regurgitation was significant ( $p$ value $<0.05$ )

\begin{tabular}{|c|c|c|c|}
\hline & & $\mathrm{A}$ & $\mathrm{B}$ \\
\hline \multirow{2}{*}{$\begin{array}{l}\text { ASD } \\
(\mathrm{mm})\end{array}$} & Range & $12-18$ & $11-19$ \\
\hline & Mean & $\begin{array}{c}13.24 \pm \\
1.74\end{array}$ & $\begin{array}{c}12.02 \pm \\
1.32\end{array}$ \\
\hline \multirow{2}{*}{$\begin{array}{l}\text { VSD } \\
(\mathrm{mm})\end{array}$} & Range & $6-11$ & $7-13$ \\
\hline & Mean & $\begin{array}{c}8.25 \pm \\
1.53\end{array}$ & $\begin{array}{c}9.34 \pm \\
1.89\end{array}$ \\
\hline \multirow{2}{*}{$\begin{array}{c}\text { PAP } \\
(\mathrm{mmHg})\end{array}$} & Range & $45-80$ & $60-90$ \\
\hline & Mean & $\begin{array}{c}61.00 \pm \\
10.07\end{array}$ & $\begin{array}{c}74.21 \pm \\
15.01\end{array}$ \\
\hline \multirow{3}{*}{ Rt AV valve } & Mild & 22 & 14 \\
\hline & Moderate & 13 & 18 \\
\hline & Sever & 5 & 8 \\
\hline \multirow{3}{*}{ Lt AV valve } & Mild & 15 & 8 \\
\hline & Moderate & 18 & 18 \\
\hline & Sever & 7 & 15 \\
\hline \multirow{3}{*}{$\begin{array}{c}\text { Rastelli } \\
\text { Classification }\end{array}$} & A & 31 & 34 \\
\hline & $\mathrm{B}$ & 9 & 6 \\
\hline & $\mathrm{C}$ & $\mathbf{0}$ & 0 \\
\hline
\end{tabular}

Table 3: Preoperative echocardiography data

In group $A$, the aortic clamp time was ranged between $45-75$ minutes with mean $56.62 \pm 9.29$ minutes; the total cardiopulmonary bypass (CPB) time was ranged between $90-140$ minutes with mean $112.87 \pm 11.48$ minutes. While group $\mathrm{B}$, the aortic clamp time was ranged between $50-90$ minutes with mean $62.64 \pm 14.21$ minutes; the total cardiopulmonary bypass (CPB) time was ranged between $90-160$ minutes with mean $121.78 \pm 18.21$ minutes. Table (4)

\begin{tabular}{|c|c|c|c|}
\cline { 3 - 4 } \multicolumn{2}{c|}{} & A & B \\
\hline $\begin{array}{c}\text { Aortic cross } \\
\text { clamp time (min) }\end{array}$ & Range & $45-75$ & $50-90$ \\
\cline { 2 - 4 } & Mean & $\begin{array}{c}56.62 \pm \\
9.29\end{array}$ & $\begin{array}{c}62.64 \pm \\
14.21\end{array}$ \\
\hline CPB time & Range & $90-140$ & $90-160$ \\
\cline { 2 - 4 }$(\min )$ & Mean & $\begin{array}{c}\mathbf{1 1 2 . 8 7} \pm \\
\mathbf{1 1 . 4 8}\end{array}$ & $\begin{array}{c}\mathbf{1 2 1 . 7 8} \pm \\
\end{array}$ \\
\cline { 2 - 4 } & & & \\
\hline
\end{tabular}

Table 4: Aortic cross clamp and CPB time

In patients repaired with double patch technique (17 patients), the VSD was closed with GorTex patch and the primum ASD was closed with autologous pericardial patch that may extend to close also the secundum ASD

In patients repaired with single patch technique (63 patients) the VSD and ASD components were closed with autologous pericardial patch.

Left AV valve was repaired with interrupted 5/0 prolene sutures in 76 patients and the other 4 patients were not repaired as they had double valve orifices. 
During cardiopulmonary bypass conventional hemofiltration was done for all patients while modified ultrafiltration (MUF) was done only for 7 patients ( 2 patients in group A and 5 in the group B)

The inotropes and vasodilators used for the patients are described in Table (5). Milrinone was used for all patients at a dose $0.7 \mathrm{mic} / \mathrm{kg} / \mathrm{min}$

\begin{tabular}{|c|c|c|c|}
\cline { 3 - 4 } \multicolumn{2}{c|}{} & A & B \\
\hline \multirow{2}{*}{$\begin{array}{c}\text { Adrenaline } \\
(\mathrm{mcg} / \mathrm{kg} / \mathrm{min})\end{array}$} & Range & $50-140$ & $100-220$ \\
\cline { 2 - 4 } & Mean & $\begin{array}{c}85.64 \pm \\
29.18\end{array}$ & $\begin{array}{c}140.54 \pm \\
70.01\end{array}$ \\
\hline \multirow{2}{*}{$\begin{array}{c}\text { Noradrenaline } \\
(\mathrm{mcg} / \mathrm{kg} / \mathrm{min})\end{array}$} & Range & $50-120$ & $100-150$ \\
\cline { 2 - 4 } & Mean & $\begin{array}{c}74.23 \pm \\
27.30\end{array}$ & $\begin{array}{c}120.32 \pm \\
25.47\end{array}$ \\
\hline & Range & $5-15$ & $10-15$ \\
\cline { 3 - 4 } $\begin{array}{c}\text { Dobutamine } \\
(\mathrm{mcg} / \mathrm{kg} / \mathrm{min})\end{array}$ & Mean & $\begin{array}{c}8.80 \pm \\
2.69\end{array}$ & $\begin{array}{c}12.32 \pm \\
2.54\end{array}$ \\
\cline { 3 - 4 } & & & \\
\hline
\end{tabular}

Table 5: Postoperative inotropes and vasodilators.
In group $A$, the time need for ventilation ranged between $21-72$ hour with mean $17.73 \pm 8.21$ hour, the period of stay in the ICU ranged between $2-10$ days with mean $4.07 \pm 2.22$ days and the total period of stay in the hospital ranged between $7-16$ days with mean $8.16 \pm 3.29$ days.

While in group $\mathrm{B}$, the time need for ventilation ranged between $36-92$ hour with mean $44.26 \pm 37.04$ hour, the period of stay in the ICU ranged between 6 - 15 days with mean $9.32 \pm 5.12$ days and the total period of stay in the hospital ranged between $11-23$ days with mean $16.11 \pm 7.54$ days. Table (6)

The $\mathrm{p}$ value between the two groups according to ventilation time, ICU and hospital stay was significant $(\mathrm{p}$ value $<0.05)$

\begin{tabular}{|c|c|c|c|c|}
\cline { 3 - 4 } \multicolumn{2}{c|}{} & A & B & \multirow{2}{*}{ P value } \\
\hline \multirow{2}{*}{ Ventilation time (h) } & Range & $21-72$ & $36-92$ & \multirow{2}{*}{0.002} \\
\cline { 2 - 4 } & Mean & $17.73 \pm 8.21$ & $44.26 \pm 37.04$ & \multirow{2}{*}{0.012} \\
\hline \multirow{2}{*}{ ICU stay (day) } & Range & $2-10$ & $6-15$ & \multirow{2}{*}{0.004} \\
\cline { 2 - 4 } & Mean & $4.07 \pm 2.22$ & $11-23$ & $16.11 \pm 7.54$ \\
\hline \multirow{2}{*}{ Hospital stay (day) } & Range & $7-19$ & & \multicolumn{2}{|c}{0.12} \\
\cline { 2 - 4 } & Mean & $10.16 \pm 4.29$ & & \\
\hline
\end{tabular}

Table 6: ICU and hospital stay

In our study, we observed patients complicated with chest infection (three in group A and nine in group B) that was managed by antibiotics and chest physiotherapy, superficial wound infection (one in group A and one in group B) that was managed by frequent dressing and antibiotics, one case of surgical bleeding in group A that was transferred again in operating room for exploration, impaired renal function (two in group A and four in group B) that was managed by peritoneal dialysis, temporal heart block ( five in group A and three in group B) that was managed with atropine and dexamethasone and recovered within 8 days, one case with permenant heart block in group B that needed permenant pace maker and pulmonary hypertensive crisis (two in group A and eight in group B) that was managed by sedation, muscle relaxant, hyperventilation, correction of electrolytes and pulmonary vasodilators drugs. Table (7)

\begin{tabular}{|l|c|c|}
\hline \multicolumn{1}{|c|}{ Complications } & A & B \\
\hline Chest infection & 3 & 9 \\
\hline Superficial wound infection & 1 & 1 \\
\hline Bleeding & 1 & 0 \\
\hline Impaired renal function & 2 & 4 \\
\hline Temporal heart block & 5 & 3 \\
\hline Permanent heart block & 0 & 1 \\
\hline Pulmonary hypertensive crisis & 2 & 8 \\
\hline
\end{tabular}

Table 7: Postoperative complications

Postoperative echocardiography showed:

No cases with residual ASD and 4 cases (10\%) with residual VSD ranging between 2- $4 \mathrm{~mm}$ in the first group, while in the second group there was no residual ASD or VSD.

In group A, there was 4 cases (10\%) with mild tricuspid regurgitation, 8 cases $(20 \%)$ with moderate tricuspid regurgitation, 9 cases $(22.5 \%)$ with mild mitral regurgitation 4 cases $(10 \%)$ with moderate mitral regurgitation and 4 cases (10\%) with sever mitral regurgitation. But in group B we found 3 cases 
(7.5\%) with mild tricuspid regurgitation, 6 cases

(15\%) with moderate tricuspid regurgitation, 1 case

$(2.5 \%)$ with sever tricuspid regurgitation, 4 cases

$(10 \%)$ with mild mitral regurgitation, 2 cases $(5 \%)$

with moderate mitral regurgitation and 2 cases $(5 \%)$

with sever mitral regurgitation. Table (8)

The $\mathrm{p}$ value between the two groups was significant ( $\mathrm{p}$ value $<0.05$ )

\begin{tabular}{|c|c|c|c|c|}
\hline & Degree & A & B & $P$ value \\
\hline \multirow{3}{*}{ Tricuspid regurgitation } & Mild & 4 & 3 & \multirow{3}{*}{0.015} \\
\hline & Moderate & 8 & 6 & \\
\hline & Sever & 0 & 1 & \\
\hline \multirow{3}{*}{ Mitral regurgitation } & Mild & 9 & 4 & \multirow{3}{*}{0.008} \\
\hline & Moderate & 4 & 2 & \\
\hline & Sever & 4 & 2 & \\
\hline
\end{tabular}

Table 8: Postoperative AV valve regurgitation

The range of postoperative systolic PAP was between $30-55 \mathrm{mmHg}$ with mean $37.23 \pm 2.57$ $\mathrm{mmHg}$ in group $\mathrm{A}$, while in group $\mathrm{B}$ the range was between $50-65 \mathrm{mmHg}$ with mean $56.82 \pm 6.29$ $\mathrm{mmHg}$. The $\mathrm{p}$ value between the two groups was significant $(\mathrm{p}$ value $<0.05)$

In group A, the mortality rate was 4 cases (10\%), 2 of them were due to low cardiac output, one due to pulmonary hypertensive crisis and one due to chest infection. While in group B, the mortality rate was 7 cases $(17.5 \%), 2$ of them due to chest infection and 5 due to pulmonary hypertensive crisis. The $\mathrm{p}$ value between the two groups was significant ( $p$ value $<$ $0.05)$.

Kaplan-Meier curve for freedom from death comparing children before and after six months of age is shown in figure 1 .

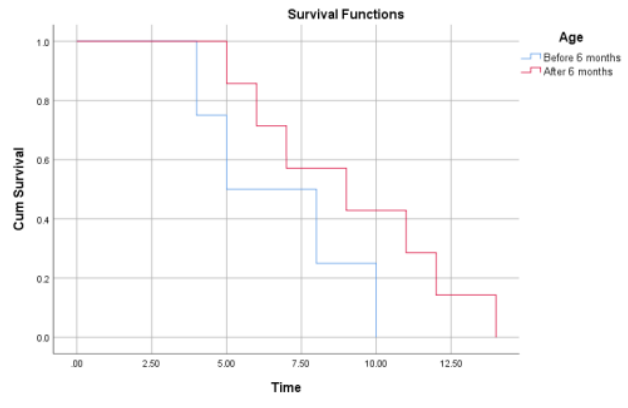

Fig. 1: Kaplan-Meier curves for freedom from death

Follow up:

All cases were normal as regard there hemodynamics, chest condition and wound scar.

No cases with residual ASD or VSD except for 1 case with residual VSD $3 \mathrm{~mm}$ in the first group.

In group A, 10 cases with moderate tricuspid regurgitation, 1 case with sever tricuspid regurgitation, 5 cases with mild mitral regurgitation, 8 cases with moderate mitral regurgitation and 7 cases with sever mitral regurgitation ( 3 of them need surgical intervention for mital repair) and pulmonary artery pressure ranged between $15-35 \mathrm{mmHg}$ with mean $20.69 \pm 5.49 \mathrm{mmHg}$.

While in group B, 5 cases with tricuspid regurgitation, 5 cases with mild mitral regurgitation, 4 cases with moderate mitral regurgitation and 2 cases with sever mitral regurgitation that need follow up with medical treatment and pulmonary artery pressure ranged between $25-40 \mathrm{mmHg}$ with mean $28.59 \pm 9.83 \mathrm{mmHg}$.

\section{DISCUSSION}

The improvement in the operative techniques and ICU management played a great role in decreasing the rate of morbidity and mortality. ${ }^{8}$

Early repair decrease the risk of development of pulmonary vascular obstructive disease. It is preferred in patients with refractory heart failure that not respond to medical treatment. ${ }^{9}$

Historically, CAVSD was successfully repaired by C. Walton Lillehei for the first time in $1955 .{ }^{10}$

There is debate about the timing of repair of CAVSD in spite of the benefits of early repair before the age of six months that do not give the same results in all patients ${ }^{9}$. In our study, we operated on 80 patients with age ranged between 3 - 11 months (mean $6.45 \pm$ 2.17 month), while Dawary et al operated on 140 patients with age below 2 years ${ }^{11}$, while Atz et al operated on 120 patients ranging between 9 days to 1.1 years (median age at surgery was 3.7 months). ${ }^{12}$

This series of patients didn't include cases of complete atrio-ventricular canal associated with repairable congenital cardiac anomalies, unbalanced complete atrio-ventricular canal and redo cases.

We studied all data about pre-operative, intraoperative and post-operative course that affect prognosis of the repair. Full analysis of immediate and early post-operative results was done. 
Patients with Down syndrome have higher incidence of morbidity rate that affect the duration of ICU stay, hospital stay and the expected life style even after excellent repair. ${ }^{13}$

In our study 58 patients are Down syndrome that represents $72.5 \%$ of patients, while it was $80 \%$ in the study of Atz et al ${ }^{12}$. In Deraz et al it was $89.6 \%$ of patients. ${ }^{14}$

Several studies confirmed that there is a relationship between the weight and the surgical result. Waiting for gaining weight may be risky as the clinical status of the patient need urgent surgical intervention. These patients are complaining of congestive heart failure and pulmonary vascular obstructive disease that they cannot coexist with it. In a study done by Prifti and colleagues ${ }^{15}$ about the relation between weight and the surgical result, they noted high incidence of reoperation for left $\mathrm{AV}$ valve regurgitation if the weight at time of repair was $<5$ $\mathrm{kg}$. Suzuki and colleagues noted high rate of left AV valve regurgitation if repair was done before age of 3 months. ${ }^{16}$

Many studies revealed that primary repair of CAVSD at young age are associated with poor outcomes. Others preferred the age of $3-6$ months as the ideal timing for intervention. ${ }^{17}$

The used surgical technique in our study was modified single patch technique in 63 patients that represents $78.75 \%$ and double patch technique in 17 patients that represents $21.25 \%$. Whie Ugaki et al used 29 children $(56.8 \%)$ operated with modified single-patch technique and 22 patients with double patch technique $(43.2 \%)^{18}$. Abdel-Raouf et al used single patch technique in 30 patients $(60 \%)$ and double patch technique in 20 patients $(40 \%) .{ }^{19}$

In our study there was 4 cases (5\%) with residual VSD ranging between 2- $4 \mathrm{~mm}$ that are in the first group that revealed also 17 cases mitral regurgitation [ 9 cases with mild mitral regurgitation 4 cases with moderate mitral regurgitation and 4 cases with sever mitral regurgitation ], while the second revealed 8 cases mitral regurgitation [ 4 cases with mild mitral regurgitation 2 cases with moderate mitral regurgitation and 2 cases with sever mitral regurgitation] Dawary et al found 33 patients with mitral regurgitation [23 cases $(16.4 \%)$ with mild AV regurgitation, $7(5 \%)$ with moderate and $3(2.1 \%)$ with severe $\mathrm{AV}$ regurgitation $]^{11}$. Atz et al found 56 (48\%) with residual VSD, 59 patients (49.1\%) with mitral regurgitation (12). Deraz et al found 5 patients (3.4\%) with residual VSD, 12 patients $(8.2 \%)$ with sever mitral regurgitation ${ }^{14}$. Ugaki et al found 4 patients $(7.8 \%)$ with residual VSD and 6 patients with mitral regurgitation ${ }^{18}$. Abdel-Raouf et al found 8 patients $(16 \%)$ with moderate mitral regurgitation and 2 patients (4\%) with sever mitral regurgitation. ${ }^{19}$

In our first group we had 5 cases $(12.5 \%)$ with temporal heart block that recovered within 8 days and none of them needed permanent pace maker, while in the second group we had 4 cases with heart block but only one of them needed insertion of permanent pace maker in comparison to Deraz et al that found 5 patients $(3.4 \%)$ with complete heart block that needed placement of a permanent pace maker ${ }^{14}$. Only 1 patient needed permanent pace maker according to Ugaki et $\mathrm{al}^{18}$. Pan et al also reported 2 patients $(2.04 \%)$ developed heart block that required a pacemaker insertion ${ }^{20}$. Abdel-Raouf et al reported 2 cases (4\%) with transient heart block which resolved well with no need for pacemaker implantation. ${ }^{19}$

In comparison to Atz et al who reported $2.5 \%$ (3 cases) mortality ${ }^{12}$, we had $13.75 \%$ (11 cases: 4 in the first group and 7 in the second group) mortality. Deraz et al reported $6.2 \%$ ( 9 cases $)^{14}$, while AbdelRaouf et al reported $6 \%$ (3 cases). ${ }^{19}$

\section{CONCLUSION}

Repair of CAVC in the first group give better results in improvement of the pulmonary artery pressure with higher incidence of reoperation for $\mathrm{Lt} \mathrm{AV}$ valve repair.

While repair in the second group give bad results in improvement of the pulmonary artery pressure with better results for the $\mathrm{Lt} \mathrm{AV}$ valve.

\section{REFERENCES}

1. Singh, R. Ramesh, Patrick S. Warren, T. Brett Reece, et al. Early Repair of Complete Atrioventricular Septal Defect Is Safe and Effective. The Annals of Thoracic Surgery. 2006; 82; 1598-1602.

2. Louis, James D. St., Upinder Jodhka, Jeffrey P. Jacobs, et al. Contemporary Outcomes of Complete Atrioventricular Septal Defect Repair: Analysis of the Society of Thoracic Surgeons Congenital Heart Surgery Database. The Journal of Thoracic and Cardiovascular Surgery.2014; 148; 2526-31.

3. Lange, Ruediger, Thomas Guenther, Raymonde Busch, et al. The Presence of Down syndrome Is Not a Risk Factor in Complete Atrioventricular Septal Defect Repair. The Journal of Thoracic and Cardiovascular Surgery. 2007; 134; 304-10.

4. Stellin, G. Surgical Treatment of Complete AV Canal Defects in Children before 3 Months of Age. European Journal of Cardio-Thoracic Surgery.2003; 23; 187-93. 
5. Mavroudis,Constantine. Atrioventricular Canal Defects. Pediatric Cardiac Surgery. 2013; 342 -60 .

6. Bakhtiary, Farhad, Judith Takacs, et al. LongTerm Results After Repair of Complete Atrioventricular Septal Defect With Two-patch Technique. The Annals of Thoracic Surgery. 2010; 89; 1239-43.

7. Stephens, Elizabeth H., Ali N. Ibrahimiye, Halit Yerebakan, et al. Early Complete Atrioventricular Canal Repair Yields Outcomes Equivalent to Late Repair. The Annals of Thoracic Surgery.2015; 99; 2109-16.

8. Ak, Koray. Atrioventricular Canal Defects: Morphologic Features and Surgical Techniques. Biomedical Journal of Scientific \& Technical Research. 2018; 10.

9. Tweddell, James S., et al. Twenty-Year Experience with Repair of Complete Atrioventricular Septal Defects. The Annals of Thoracic Surgery. 1996; 62; 419-24.

10. Louis, James D. St., et al. Contemporary Outcomes of Complete Atrioventricular Septal Defect Repair: Analysis of the Society of Thoracic Surgeons Congenital Heart Surgery Database. The Journal of Thoracic and Cardiovascular Surgery.2014; 148; 2526-31.

11. Dawary, Mohannad Ali, Faisal Dkhalallah Alshamdin, et al. Outcomes of Surgical Repair of Complete Atrioventricular Canal Defect in Patients Younger than 2 Years of Age. Annals of Saudi Medicine.2019; 6; 422-5.

12. Atz, Andrew M., John A. Hawkins, Minmin $\mathrm{Lu}$, Meryl S. et al. Surgical Management of Complete Atrioventricular Septal Defect: Associations with Surgical Technique, Age, and Trisomy 21. The Journal of Thoracic and Cardiovascular Surgery. 2011; 141; 1371-9.
13. Tumanyan, Margarita R., et al. Repair of Infants with Down syndrome: Outcomes and Long-Term Results. Pediatric Cardiology. 2014; 36; 71-75.

14. Deraz, Salem, and Mohamed Ismail. Single Patch Technique versus Double Patch Technique in Repair of Complete Atrioventricular Septal Defect. The Egyptian Heart Journal.2014; 66; 177-82.

15. Prifti E, Bonacchi M, Bernabei M, et al. Repair of complete atrioventricular septal defects in patients weighing less than $5 \mathrm{~kg}$. Ann Thorac Surg. 2004; 77; 1717-26.

16. Suzuki T, Bove EL, Devaney EJ, et al. Results of definitive repair of complete atrioventricular septal defect in neonates and infants. Ann Thorac Surg. 2008; 86; 596-602.

17. Stephens, Elizabeth H., et al. Early Complete Atrioventricular Canal Repair Yields Outcomes Equivalent to Late Repair. The Annals of Thoracic Surgery.2015; 99; 2109-16.

18. Ugaki, Shinya, Nee S. Khoo, David B. Ross, Ivan M. Rebeyka, and Ian et al. datia. Modified Single-Patch Compared With Two-Patch Repair of Complete Atrioventricular Septal Defect. The Annals of Thoracic Surgery.2014; 97; 666-71.

19. Mohamed E. Abdel-Raouf, Hosny M. ElSallab, and Muhammed Sharaa, Complete Atrioventricular Septal Defects 'Outcome of Different Techniques. The Medical Journal of Cairo University. 2019; 87; 2425-30.

20. Pan G, Song L, Zhou X, et al. Complete Atrioventricular Septal Defect: Comparison of Modified Single-Patch Technique with TwoPatch Technique in Infants. Journal of Cardiac Surgery. 2014; 29 (2):2. 